\title{
Soil thermal responses around a field-scale energy pile
}

\author{
Mohammed Faizal ${ }^{1, *}$, Aria Moradshahi ${ }^{1}$, Abdelmalek Bouazza ${ }^{1}$ and John S. McCartney ${ }^{2}$ \\ ${ }^{1}$ Monash University, Department of Civil Engineering, 23 College Walk, Clayton, Vic. 3800, Australia \\ ${ }^{2}$ University of California San Diego, Department of Structural Engineering, 9500 Gilman Drive, La Jolla, CA 92093-0085, USA
}

\begin{abstract}
This paper presents the results of field and numerical studies on the soil thermal response around a field-scale energy pile. The investigation focuses on the effect of monotonic heating, monotonic cooling, and daily cyclic heating/cooling of the energy pile on the soil thermal response. The soil temperature changes are found to be highest near the edge of the energy pile and reduce with increasing radial distance for all operating modes. The cyclic temperature changes of the energy pile impose lower ground temperature changes compared to monotonic temperature changes due to frequent ground thermal recoveries during each thermal cycle. The soil zone experiencing radial thermal influence is also smaller for cyclic temperature changes of the energy pile. The results generally indicate that cyclic heating/cooling of the energy pile will improve geothermal energy utilization with lower thermal impacts on the ground for long term operations of ground source heat pumps.
\end{abstract}

\section{Introduction}

Energy piles are generally subjected to monotonic or cyclic temperature changes, depending on the season of operation or daily thermal energy requirements of the building. They are subjected to daily cyclic temperatures from intermittent operations of the ground source heat pump (GSHP) with natural or forced ground thermal recoveries during the non-operating times of the GSHP [1 - 9].

The heat transfer between the heat exchanger loops, the concrete, and the ground leads to changes in the temperatures of the soils surrounding the piles. The soil temperatures around the energy pile vary depending on the magnitude of inlet fluid temperatures and the magnitude of pile temperature changes. Field studies on isolated energy piles subjected to monotonic temperatures have indicated that ground temperature changes are greatest near the edge of the energy pile and reduce with increasing radial distance [9-18].

There are, however, limited studies conducted on the effects of daily cyclic heating/cooling of energy piles at a field scale $[7,17]$. These limited studies have indicated that cyclic temperature changes improve geothermal energy utilization and induce lower ground temperature changes compared to monotonic temperature operations.

Cyclic temperature operating modes of GSHPs therefore have the potential of reducing the radial thermal influence zone of the soil around an energy pile compared to monotonic temperatures. This would be beneficial in reducing thermal interactions between energy piles operating in groups and improving geothermal energy utilization and reducing ground temperature changes for long term operations.
This paper examines the impact of monotonic and daily cyclic temperature changes of an energy pile on the surrounding soil temperatures, experimentally and numerically. A field-scale energy pile was subjected to monotonic heating, monotonic cooling, and daily cyclic heating/cooling for the above purpose.

\section{Experimental setup and procedure}

The experiments were conducted on a field-scale energy pile installed in dense sand. The diameter and the length of the pile was $0.6 \mathrm{~m}$ and $16.1 \mathrm{~m}$, respectively. There were no head loads on the pile, and the pile head was exposed to the atmosphere. The pile was instrumented with vibrating wire strain gauges (VWSG), and two soil boreholes located $0.5 \mathrm{~m}$ and $2 \mathrm{~m}$, respectively, from the edge of the pile, were instrumented with thermocouples to a depth of $16 \mathrm{~m}$ (Figure 1).

The geological and instrumentation details of the pile are also shown in Figure 1. There were two Osterberg Cells installed at depths of $10 \mathrm{~m}$ and $14 \mathrm{~m}$, respectively, which were previously used to study shaft resistance by partially translating the upper $10 \mathrm{~m}$ pile section [19]. Three heat exchanger U-loops were installed in the pile to a depth of $14.2 \mathrm{~m}$. The U-loops pipes were made of highdensity polyethylene (HDPE) with inner and outer diameters of $20 \mathrm{~mm}$ and $25 \mathrm{~mm}$, respectively.

Three scenarios were investigated; these are: i) monotonic heating with inlet fluid temperatures of $45^{\circ} \mathrm{C}$, ii) monotonic cooling with inlet fluid temperatures of $5^{\circ} \mathrm{C}$, and daily cyclic temperature changes with 16 hours of cooling followed by 8 hours of heating with a temperature range of $7^{\circ} \mathrm{C}-55^{\circ} \mathrm{C}$. The inlet fluid temperatures are

\footnotetext{
* Corresponding author: mohammed.faizal@monash.edu
} 
shown in Figure 2. The field data used in the current investigation was previously reported in $[7,8,14,19]$.

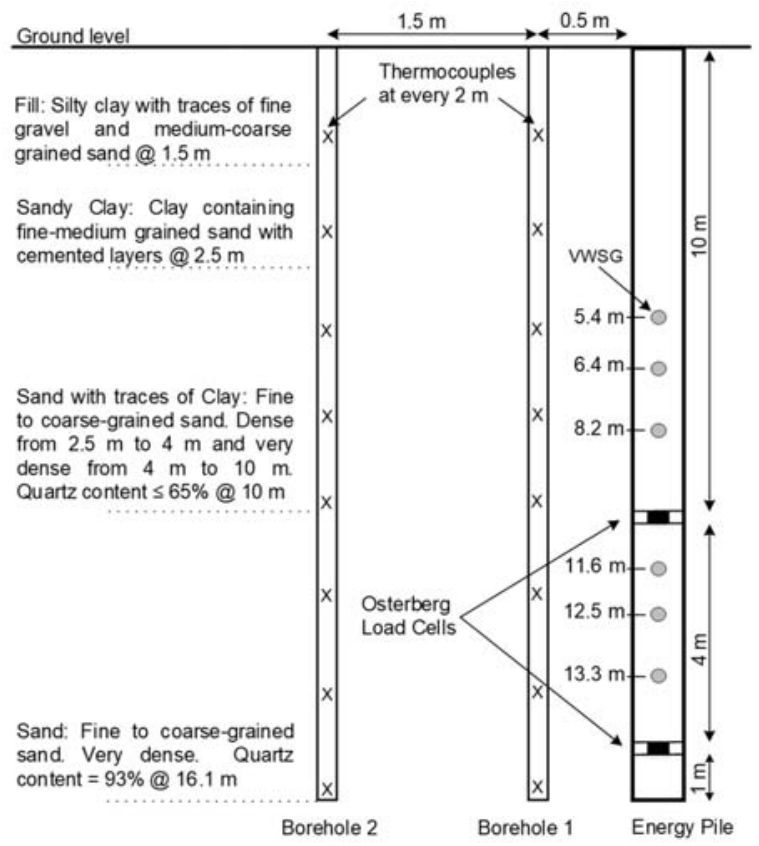

Fig. 1. Schematic diagram of the field setup [19].

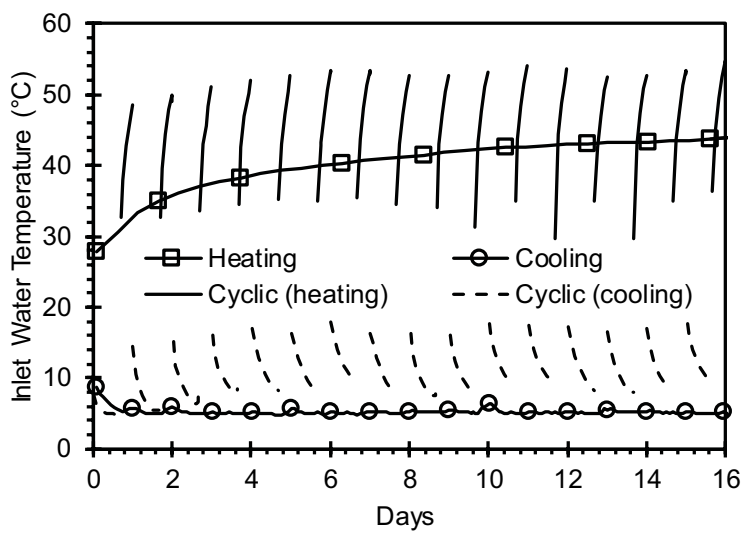

Fig. 2. Inlet fluid temperatures.

\section{Numerical modelling}

A 3D numerical model was developed in COMSOL Multiphysics using the heat conduction equation and the field boundary conditions. The dimensions of the numerical model were $30 \times 15 \times 15 \mathrm{~m}^{3}$. The model consisted of 326524 mesh elements from which 92178 elements were used to describe the energy pile. The pile and the soil thermal properties used in the numerical model were estimated from previous studies conducted on the site $[14,15,19,20]$.

The ground temperatures from field tests were used to calibrate the numerical model. A heat source boundary was considered at the pile-soil interface based on the pile temperatures recorded in the field. Roller and fixed boundary conditions were applied on the sides and bottom of the model, respectively. The initial temperatures of the ground and the energy pile were the same as those recorded at the beginning of each experiment.

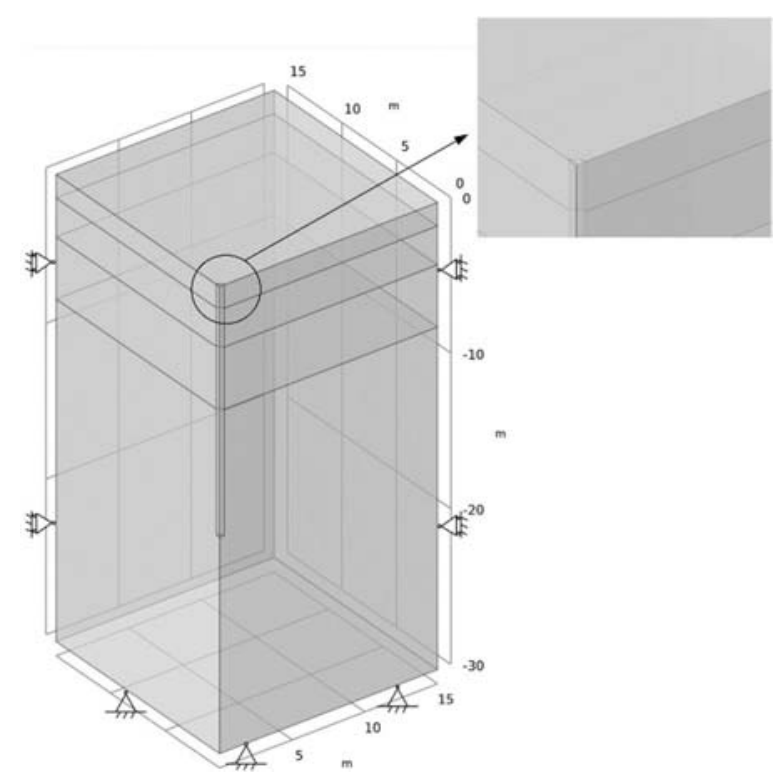

Fig. 3. Dimensions and boundary conditions of the numerical model.

\section{Results and discussions}

The pile temperatures for all three experiments are shown in Figure 4a. The pile temperatures reached up to $38^{\circ} \mathrm{C}$ during monotonic heating and reduced to $7^{\circ} \mathrm{C}$ during monotonic cooling, and varied between $10^{\circ} \mathrm{C}$ to $34^{\circ} \mathrm{C}$ during cyclic heating/cooling. The variations of pile temperatures led to variations in the surrounding soil temperatures.

The differences between pile temperatures recorded during the experiments and the initial, thermally undisturbed, soil temperatures are shown in Figure $4 \mathrm{~b}$. The temperature differences during monotonic heating and cooling were $20^{\circ} \mathrm{C}$ and $-10^{\circ} \mathrm{C}$, respectively. The larger temperature difference for monotonic heating imposed higher soil temperature changes compared to monotonic cooling, as discussed later. It would have been ideal to have similar temperature differences for the two monotonic temperature experiments for a better comparison of the results. This comparison was, however, not possible due to the different equipment used for heating and cooling purposes. The temperature difference ranged between $-10^{\circ} \mathrm{C}$ to $17^{\circ} \mathrm{C}$ for the cyclic temperature changes.

The experimental and numerical soil temperature results for all the experiments are shown in Figure 5. The numerical results matched well with the field data. The soil temperature changes are most significant closer to the pile at a radial distance, $R$, of $0.5 \mathrm{~m}$. There are minimal changes in soil temperatures at $\mathrm{R}=2 \mathrm{~m}$, for all the experiments. Cyclic temperatures (Figure 5c) imposed lower soil temperature changes compared to monotonic 

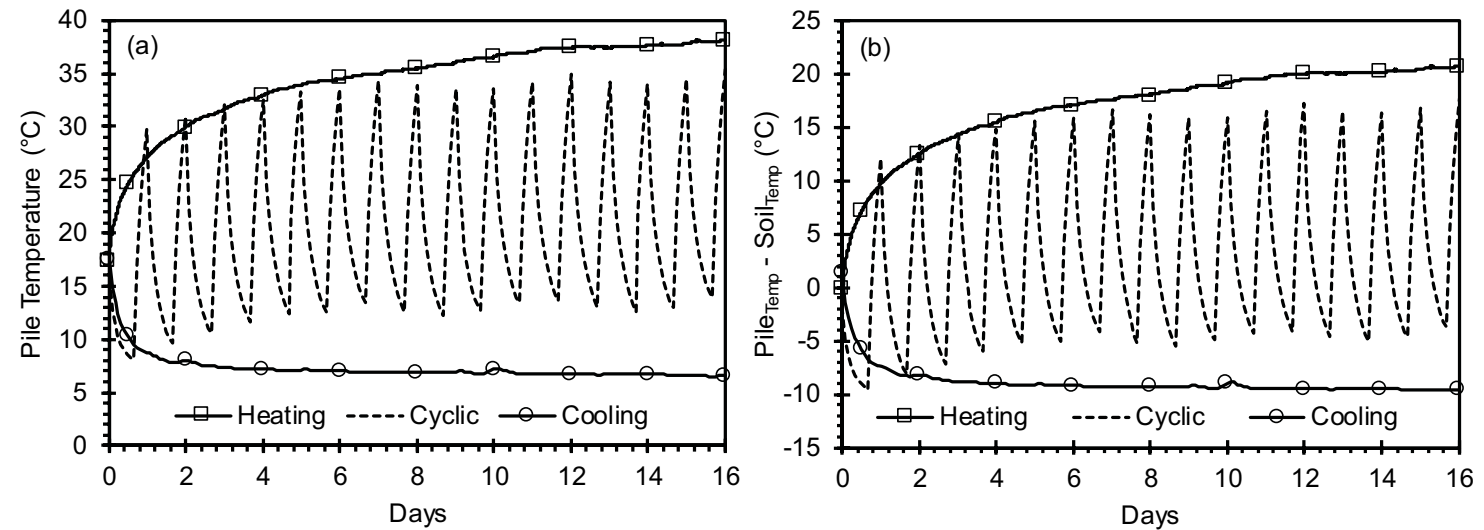

Fig. 4. Pile temperatures variations: a) pile temperatures at $d=5.4 \mathrm{~m}$, and b) difference between pile temperatures $(\mathrm{d}=5.4 \mathrm{~m})$ and initial soil temperatures $(d=6 \mathrm{~m})$.
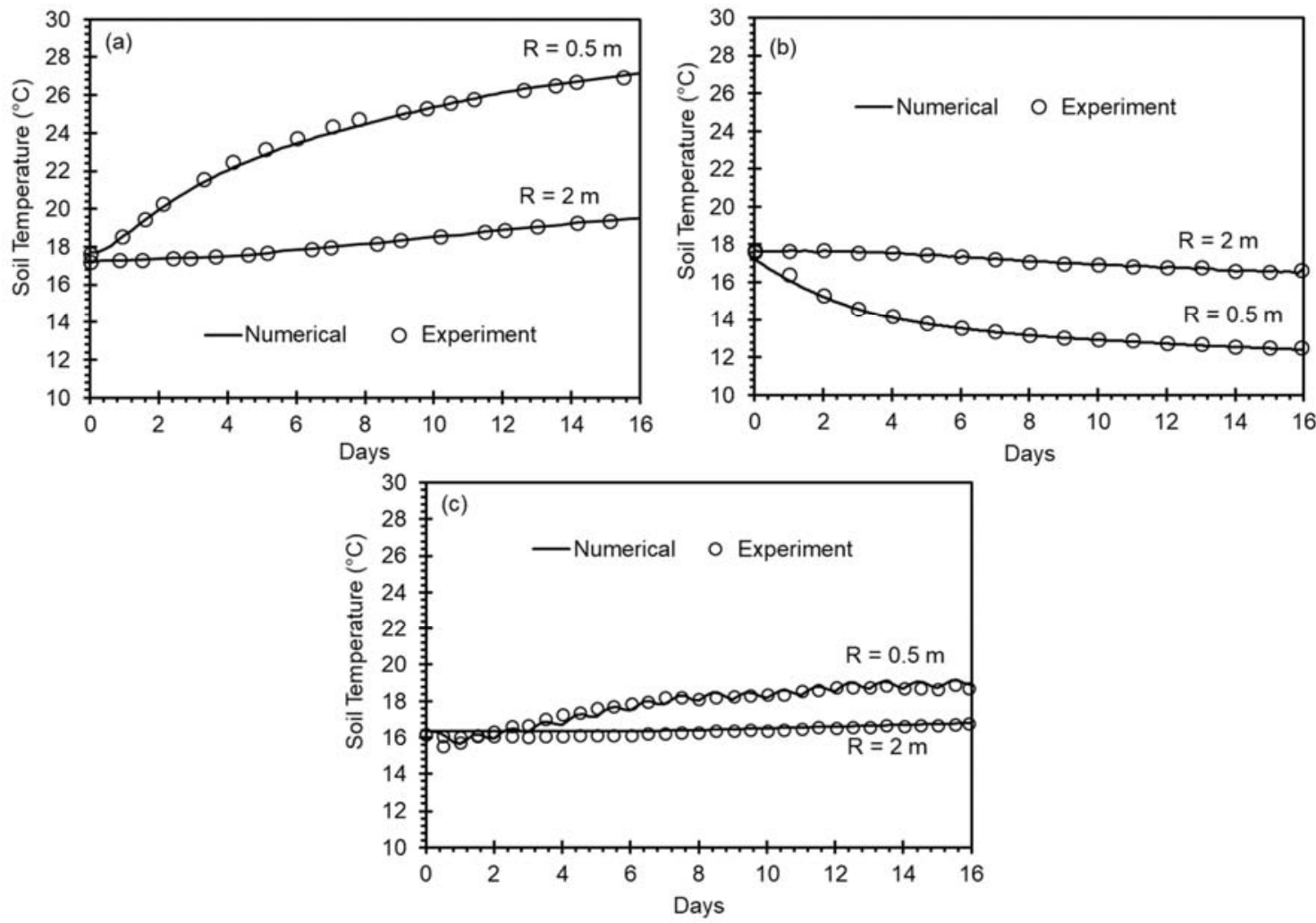

Fig. 5. Soil temperatures with numerical validation at depth of $6 \mathrm{~m}$, for: a) monotonic heating, b) monotonic cooling, and c) cyclic.

heating (Figure 5a) and monotonic cooling (Figure 5b). The soil temperature changes during monotonic heating are higher compared to that during monotonic cooling due to higher pile temperatures (and hence higher differences between pile and soil temperatures) developed during monotonic heating, as shown in Figure 4. The validated numerical model was used to investigate the soil temperature variations at different radial distances from the edge of the energy pile.

The change in soil temperatures with respect to initial conditions, $\Delta T_{\text {Soil }}$, at a depth of $6 \mathrm{~m}$ and different radial distances from the edge of the energy pile is shown in Figure 6. The soil is assumed to be homogeneously distributed at different radial distances. The ground experiences highest temperature changes near the energy pile at $\mathrm{R}=0.2 \mathrm{~m}$ and reduce with increasing radial distance, for all experiments. Cyclic heating/cooling induces lower overall ground temperature changes compared to monotonic heating and cooling. The thermal gradient between the energy pile and the soil is frequently reversed in the cyclic experiment; hence lower ground temperature changes are induced during cyclic heating/cooling of the energy pile.

The temperature amplitudes in the energy pile during cyclic heating/cooling are transferred to the soil near the energy pile (Figure 6c). This temperature amplitude is 

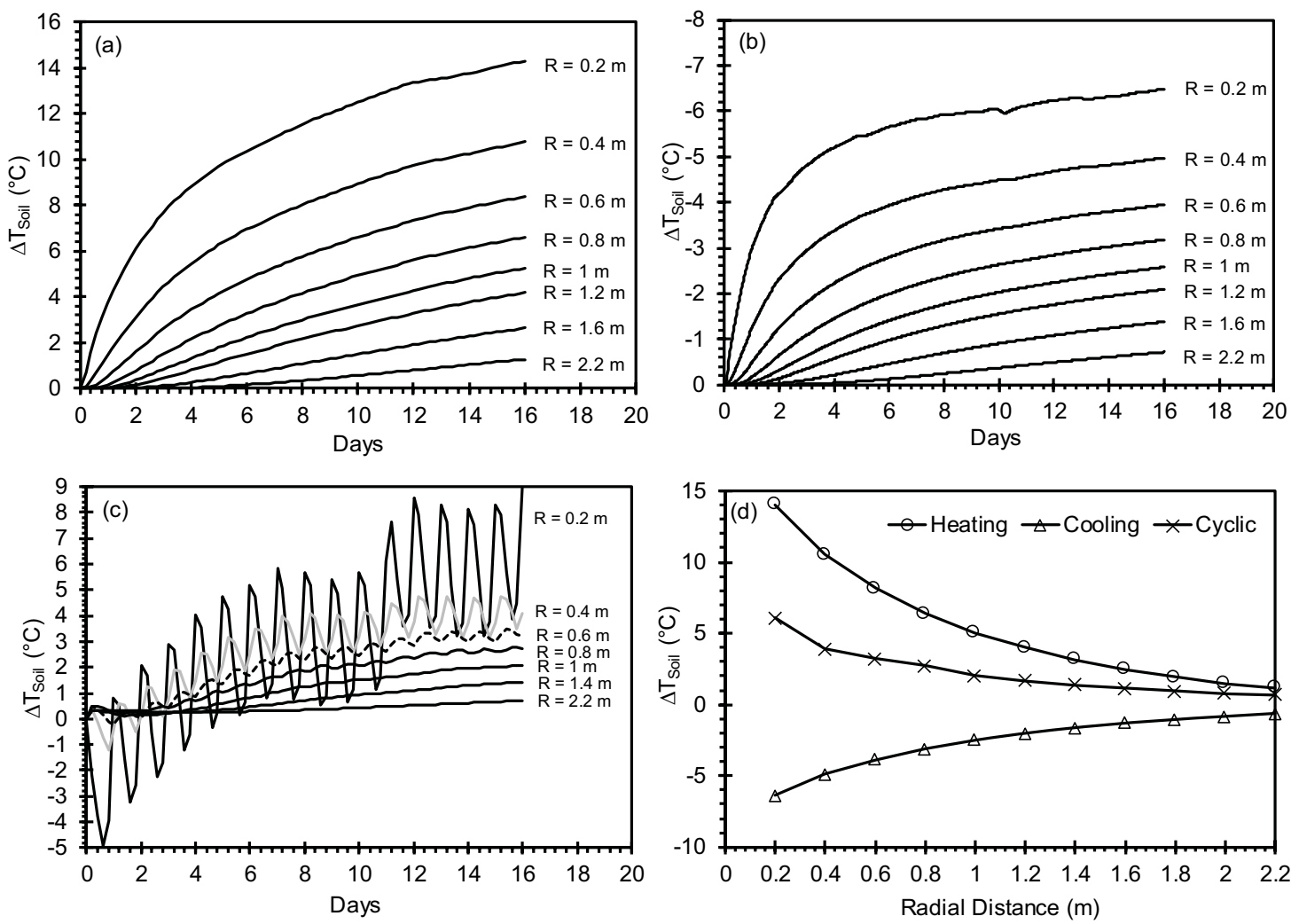

Fig. 6. Change in soil temperatures, $\Delta T_{\text {soil }}$, at depth of $6 \mathrm{~m}$ and different radial distances, $R$ : a) heating, cooling, cyclic, and d) comparison of all three modes at Day 15.

highest at $\mathrm{R}=0.2 \mathrm{~m}$ and becomes negligible after $\mathrm{R}=0.6 \mathrm{~m}$. These results indicate that the immediate effects of frequent cyclic temperatures will be up to given radial distances from the piles; hence this region will have higher heat exchange with the energy pile due to frequent temperature reversals compared to farther radial regions.

The $\Delta T_{\text {Soil }}$ magnitudes variation with increasing radial distance for $\mathrm{d}=6 \mathrm{~m}$ and Day 15 are shown in Figure 6d. Average magnitudes are shown for the cyclic temperature experiments. The $\Delta T_{\text {Soil }}$ magnitudes reduce gradually with increasing radial distance for all three cases. Cyclic heating/cooling imposes lower ground temperature changes compared to monotonic heating and cooling at corresponding radial distances. These results indicate that cyclic temperature changes of the energy pile affect a low volume of soil and hence reduces the radial thermal influence zone of the surrounding soils compared to monotonic temperature changes of the energy pile.

Cyclic temperature operations of energy piles are thus expected to be beneficial in reducing thermal interactions between energy piles operating in groups. This will help mitigate cumulative increases or reductions in ground temperature and improve heat exchange capacity of energy piles for long term operations.

\section{Conclusions}

This paper examined the distribution of soil temperature around a field-scale energy pile installed in dense sand. The energy pile was subjected to monotonic heating, monotonic cooling and daily cyclic temperature changes. A numerical study was used to complement the field results by evaluating the soil temperatures at different radial distances from the edge of the energy pile. The soil temperature changes were greatest near the energy pile and reduced with increasing radial distance, for all operating modes. Cyclic heating/cooling imposed lower soil temperature changes compared to monotonic heating and monotonic cooling. The soil radial thermal influence zone for cyclic heating/cooling was, therefore, lower than monotonic temperatures. These results indicate that cyclic temperature operations of ground source heat pumps will be beneficial in preventing long term cumulative soil temperature changes; hence improving geothermal energy usage, compared to monotonic temperatures. Lower soil temperatures and lower radial thermal influence zone during cyclic temperature changes of energy piles will also be beneficial in reducing thermal interactions between energy piles operating in groups.

The authors acknowledge the support of the project sponsors. This research was supported under the Australian Research Council's Linkage Projects funding scheme (project number LP120200613) by Vibropile Pty. Ltd., Golder Associates Pty. Ltd. and GeoExchange Australia Pty. Ltd. The authors also acknowledge the Australian Government Research Training Program Scholarships provided to the first and the second author. The U.S. National Science Foundation grant CMMI-0928159 supported the fourth author. 


\section{References}

1. H. Brandl. Energy foundations and other thermoactive ground structures. Géotechnique, 56(2), 81 122 (2006)

2. M. Yi, Y. Hongxing, and F. Zhaohong. Study on hybrid ground-coupled heat pump systems. Energ Buildings, 40 (11), 2028-2036 (2008)

3. C.J. Wood, H. Liu, and S.B. Riffat. Comparison of a modelled and field tested piled ground heat exchanger system for a residential building and the simulated effect of assisted ground heat recharge. Int. J. of LowCarbon Tec., 5, 137 - 143 (2010)

4. K.D. Murphy and J.S. McCartney. Seasonal response of energy foundations during building operation. Geotech. Geol. Eng., 33, 343-356 (2015)

5. L. Dai, S. Li, L. DuanMu, X. Li, Y. Shang, and M. Dong. Experimental performance analysis of a solar assisted ground source heat pump system under different heating operation modes. Appl. Therm. Eng., 75, 325-333 (2015)

6. J.S. McCartney, and K.D. Murphy. Investigation of potential dragdown/uplift effects on energy piles. Geomech. Energ. Envir., 10, 21 - 28 (2017)

7. M. Faizal, A. Bouazza and R.M. Singh. An experimental investigation of the influence of intermittent and continuous operating modes on the thermal behaviour of a full scale geothermal energy pile. Geomech. Energ. Envir., 8, 8 - 29 (2016)

8. M. Faizal, A. Bouazza, C. Haberfield, and J.S. McCartney. Axial and radial thermal responses of a field scale energy pile under monotonic and cyclic temperature changes. J. Geotech. Geoenviron, 144(10), 10.1061/(ASCE)GT.1943-5606.0001952 (2018)

9. M. Faizal, A. Bouazza, J.S. McCartney, and C. Haberfield. Effects of cyclic temperature variations on the thermal response of an energy pile under a residential building. J. Geotech. Geoenviron, 145 (10), 10.1061/(ASCE)GT.1943-5606.0002147 (2019)

10. X. Li, Y. Chen, Z. Chen and J. Zhao. Thermal performances of different types of underground heat exchangers. Energ Buildings, 38, 543 - 547 (2006)

11. P.J. Bourne-Webb, B. Amatya, K. Soga, T. Amis, C. Davidson, and P. Payne. Energy pile test at Lambeth College, London: geotechnical and thermodynamic aspects of pile response to heat cycles. Géotechnique, 59(3), 237 - 248 (2009)

12. S. You, X. Cheng, H. Guo, and Z. Yao. In-situ experimental study of heat exchange capacity of CFG pile geothermal exchangers. Energy and Buildings, 79, 23 - 31 (2014)

13. K.D. Murphy, J.S. McCartney, and K.S. Henry. Evaluation of thermo-mechanical and thermal behavior of full-scale energy foundations. Acta Geotech., 10(2), 179 - 195 (2015)

14. R.M. Singh, A. Bouazza and B. Wang. Near-field ground thermal response to heating of a geothermal energy pile: observations from a field test. Soils and Foundations, 55(6), 1412 - 1426 (2015)

15. K.L. Yu, R.M. Singh, A. Bouazza, and H.H. Bui. Determining soil thermal conductivity through numerical simulation of a heating test on a heat exchanger pile. Geotech. Geol. Eng., 33(2), 239 - 252 (2015)

16. Y. Chen, J Xu, H. Li, L. Chen, C.W.W. Ng, and H. Liu. Performance of a prestressed concrete pipe energy pile during heating and cooling. J. Perform. Construct. Fac., 31 (3), 10.1061/(ASCE)CF.19435509.0000982 (2017)

17. M. Faizal and A. Bouazza, A. Energy utilization and ground temperature distribution of a field scale energy pile under monotonic and cyclic temperature changes. In: Proceedings of China-Europe Conference on Geotechnical Engineering, Vienna, Austria. Edited by W. Wu and H.-S. Yu. Springer Nature, Switzerland, pp. 1591-1594, 2018 (2018)

18. Y. Guo, G. Zhang, and S. Liu. Investigation on the thermal response of full-scale PHC energy pile and ground temperature distribution in multi-layer strata. Appl. Therm. Eng., 143, 836 - 848 (2018)

19. B. Wang A. Bouazza R.M. Singh, C. Haberfield, D. Barry-Macaulay, and S. Baycan. Posttemperature effects on shaft capacity of a full-scale geothermal energy pile. J. Geotech. Geoenviron., 141 (4), 10.1061/(ASCE)GT.1943-5606.0001266，04014125$1-12(2015)$

20. D. Barry-Macaulay, A. Bouazza, R.M. Singh, B. Wang, and P.G. Ranjith. Thermal conductivity of soils and rocks from the Melbourne (Australia) region. Eng. Geo., 164, 131 - 138 (2013) 